\title{
Molecular Comparison of Imatinib-Naïve and Resistant Gastrointestinal Stromal Tumors: Differentially Expressed microRNAs and mRNAs
}

\author{
Azadeh Amirnasr ${ }^{1}$, Caroline M.M. Gits ${ }^{1}$, Patricia F. van Kuijk ${ }^{1}$, Marcel Smid ${ }^{1}$, \\ Anne L.M. Vriends ${ }^{1}$, Piotr Rutkowski ${ }^{2}$, Raf Sciot ${ }^{3}$, Patrick Schöffski ${ }^{4,5}$, Maria Debiec-Rychter ${ }^{6}$, \\ Stefan Sleijfer ${ }^{1}$ and Erik A. C. Wiemer ${ }^{1, *(1)}$ \\ 1 Department of Medical Oncology, Erasmus MC Cancer Institute, Erasmus University Medical Center, 3015 \\ CN Rotterdam, The Netherlands; a.amirnasr@erasmusmc.nl (A.A.); carolinegits@hotmail.com (C.M.M.G.); \\ p.vankuijk@erasmusmc.nl (P.F.v.K.); m.smid@erasmusmc.nl (M.S.); a.vriends@erasmusmc.nl (A.L.M.V.); \\ s.sleijfer@erasmusmc.nl (S.S.) \\ 2 Department of Soft Tissue/Bone Sarcoma and Melanoma, Marie Skłodowska-Curie Institute-Oncology \\ Center, 02781 Warsaw, Poland; piotr.rutkowski@coi.pl \\ 3 Department of Pathology, University Hospitals Leuven, Katholieke Universiteit Leuven, 3000 Leuven, \\ Belgium; raf.sciot@uzleuven.be \\ 4 Department of General Medical Oncology, Leuven Cancer Institute, University Hospitals Leuven, \\ Katholieke Universiteit Leuven, 3000 Leuven, Belgium; patrick.schoffski@uzleuven.be \\ 5 Research Unit Laboratory of Experimental Oncology, Department of Oncology, Faculty of Medicine, \\ Katholieke Universiteit Leuven, 3000 Leuven, Belgium \\ 6 Department of Human Genetics, University Hospitals Leuven, Katholieke Universiteit Leuven, \\ 3000 Leuven, Belgium; maria.debiec-rychter@kuleuven.be \\ * Correspondence: e.wiemer@erasmusmc.nl; Tel.: +31-10-704-4357
}

Received: 20 May 2019; Accepted: 19 June 2019; Published: 24 June 2019

\begin{abstract}
Despite the success of imatinib in advanced gastrointestinal stromal tumor (GIST) patients, $50 \%$ of the patients experience resistance within two years of treatment underscoring the need to get better insight into the mechanisms conferring imatinib resistance. Here the microRNA and mRNA expression profiles in primary (imatinib-naïve) and imatinib-resistant GIST were examined. Fifty-three GIST samples harboring primary KIT mutations (exon 9; $\mathrm{n}=11$ /exon 11; $\mathrm{n}=41$ /exon 17; $n=1)$ and comprising imatinib-naïve (IM-n) $(n=33)$ and imatinib-resistant (IM-r) $(n=20)$ tumors, were analyzed. The microRNA expression profiles were determined and from a subset (IM- $n, n=14$; IM-r, $n=15$ ) the mRNA expression profile was established. Ingenuity pathway analyses were used to unravel biochemical pathways and gene networks in IM-r GIST. Thirty-five differentially expressed miRNAs between IM-n and IM-r GIST samples were identified. Additionally, miRNAs distinguished IM-r samples with and without secondary KIT mutations. Furthermore 352 aberrantly expressed genes were found in IM-r samples. Pathway and network analyses revealed an association of differentially expressed genes with cell cycle progression and cellular proliferation, thereby implicating genes and pathways involved in imatinib resistance in GIST. Differentially expressed miRNAs and mRNAs between IM-n and IM-r GIST were identified. Bioinformatic analyses provided insight into the genes and biochemical pathways involved in imatinib-resistance and highlighted key genes that may be putative treatment targets.
\end{abstract}

Keywords: GIST; miRNA; mRNA expression; imatinib; drug resistance; gene networks; IPA pathway analysis 


\section{Introduction}

Gastrointestinal stromal tumors (GISTs) are rare mesenchymal malignancies associated with the gastrointestinal tract that originate from the interstitial cells of Cajal (ICC) or precursors thereof [1]. GISTs and ICC share morphological and immunophenotypic features, notably the expression of KIT and CD34. Molecularly, GISTs are characterized by the presence of oncogenic gain-of-function mutations in KIT ( $80 \%$ of cases) or PDGFRA ( 10\% of cases) [2,3]. KIT and PDGFRA mutations are absent in the so-called wild-type GISTs ( $10 \%$ of cases) that may contain mutations in $B R A F, N F 1$, or defects of the succinate dehydrogenase (SDH) complex [4]. The constitutive activation of KIT and PDFGRA signaling in the majority of GISTs drives tumor growth through the activation of downstream signaling cascades such as the RAS-RAF-MAPK, PI3K-AKT, and STAT3 pathways facilitating cell proliferation and survival [5]. The advent of the tyrosine kinase inhibitor imatinib mesylate, which targets both KIT and PDGFRA, has dramatically improved the outcome of patients with advanced disease [6,7]. Despite this great progress in GIST treatment and the fact that approximately $10 \%$ of the patients benefit for more than 10 years from imatinib [8], the majority of patients eventually develop imatinib resistance (acquired resistance) [8] with about 10\% of GIST patients experiencing progression already within 6 months of start of therapy (intrinsic resistance) [6,7]. Where in intrinsic resistant cases in particular KIT exon 9 mutations or PDGFRA D842V mutations are involved [9], acquired resistance may occur because of secondary mutations within KIT that interfere with the binding of imatinib [10-14]. These resistance-causing secondary mutations cluster in two regions: (i) ATP-binding pocket (encoded by exons 13 and 14), and (ii) kinase catalytic regions/activation loop (encoded by exons 17 and 18). Such secondary mutations leading to acquired resistance are observed in approximately $50 \%$ of GIST patients. The remaining cases with acquired resistance display alternative resistance mechanisms that are much less defined and include KIT and PDFRA amplification [11,13] and receptor tyrosine kinase switches from KIT to activation of FAK, FYN, or AXL [15-17].

A better understanding of the causes yielding imatinib resistance is necessary to improve treatment and outcomes. Here we performed a molecular comparison between a unique set of imatinib-naïve (IM-n) GIST samples $(n=33)$ and imatinib-resistant (IM-r) GIST samples $(n=20)$ focusing on microRNA and mRNA expression to reveal molecular pathways associated with imatinib resistance.

\section{Results}

\subsection{Differentially Expressed microRNAs between Imatinib-Nä̈ve and Imatinib-Resistant GIST Samples}

To investigate the molecular events underlying the acquisition of imatinib resistance in GIST we first determined the miRNA expression profiles in fresh frozen IM- $n(n=33)$ and IM-r $(n=20)$ GIST samples (Table 1). All imatinib resistant GIST patients displayed resistance after more than 6 months of imatinib treatment implicating acquired resistance mechanisms. Thirty-five significantly $(p<0.01$ and False Discovery Rate (FDR) $<20 \%$ ) differentially expressed miRNAs were detected between the two groups (Figure 1, Table S1). Figure 1 depicts the heat map from a supervised hierarchical clustering. Two main clusters were discerned, one cluster contained $82 \%$ of the IM-n samples and the other cluster included $85 \%$ of all IM-r samples. A number of samples of both IM-r and IM-n GISTs were found to miscluster, a fact that could not readily be explained by differences in malignancy risk or tumor location.

Secondary mutations in KIT are a frequent cause of imatinib-resistance in GIST. In the 20 IM-r samples that we analyzed, nine displayed secondary mutations in KIT exon $13(\mathrm{n}=3)$ and KIT exon 17 $(n=6)$, whereas in the remainder $(n=11)$ no secondary mutations were observed (Table 1$)$. When we compared the miRNA expression profiles of IM-r samples with and without secondary mutations, we identified 22 miRNAs that were significantly $(p<0.01)$ differentially expressed and almost completely separated the two groups (Figure 2, Table S2). This suggests miRNA biomarker profiles may be associated with the presence/absence of secondary mutations. 
Table 1. Patient and tumor characteristics.

\begin{tabular}{|c|c|c|c|c|c|}
\hline \multicolumn{6}{|c|}{ Gastrointestinal Stromal Tumors Imatinib-Naïve (IM-n) } \\
\hline Male & $\mathrm{n}=23$ & & & & \\
\hline Female & $\mathrm{n}=10$ & & & & \\
\hline Median age (range) & $65(41-85)$ & & & & \\
\hline Sample code & KIT mutation status & Location & Risk of malignancy * & miRNA & mRNA \\
\hline X1KIT11 & p.V560D/KIT11 & Small intestine & intermediate & $\checkmark$ & $\checkmark$ \\
\hline X4KIT11 & p.W557_V559delinsF/KIT11 & Small intestine & high & $\checkmark$ & $\checkmark$ \\
\hline X6KIT11 & p.W557R/KIT11 & Small intestine & overtly malignant $* *$ & $\checkmark$ & \\
\hline X8KIT11 & p.L576_R588dup/KIT11 & Stomach & intermediate & $\checkmark$ & $\checkmark$ \\
\hline X9.2.KIT11 & p.W557_V559delinsF/KIT11 & Stomach & high & $\checkmark$ & \\
\hline X10KIT11 & p.W557R/KIT11 & Stomach & intermediate & $\checkmark$ & \\
\hline X12KIT11 & p.K550_V555del/KIT11 & Stomach & high & $\checkmark$ & \\
\hline X14KIT11 & p.581_590insKWEFPRNRLS/KIT11 & Stomach & intermediate & $\checkmark$ & $\checkmark$ \\
\hline X23KIT11 & p.W557_K558del/KIT11 & Stomach & intermediate & $\checkmark$ & \\
\hline X24KIT11 & p.V554D/KIT11 & Stomach & intermediate & $\checkmark$ & $\checkmark$ \\
\hline X25KIT11 & $\begin{array}{l}\text { p.W557_G592dup } \\
\text { (c.1669_1774 + 2dup)/KIT11 }\end{array}$ & Stomach & high & $\checkmark$ & \\
\hline X26KIT11 & p.K558_V559delinsN (AAT) homo/KIT11 & Mediastinum & high & $\checkmark$ & \\
\hline X34KIT11 & p.W557_V560delinsF/KIT11 & Stomach & high & $\checkmark$ & \\
\hline X35KIT11 & p.V560D/KIT11 & Stomach & overtly malignant & $\checkmark$ & $\checkmark$ \\
\hline X39KIT11 & p.L576P/KIT11 & Duodenum & intermediate & $\checkmark$ & $\checkmark$ \\
\hline X40KIT9 & p.A502_Y503dup/KIT9 & Colon & overtly malignant & $\checkmark$ & \\
\hline X45KIT11 & p.K550_K558delinsG/KIT11 & Small intestine & overtly malignant & $\checkmark$ & \\
\hline X47KIT11 & p.V559A/KIT11 & Stomach & low & $\checkmark$ & \\
\hline X48KIT11 & p.V560A/KIT11 & Duodenum & intermediate & $\checkmark$ & $\checkmark$ \\
\hline X53KIT11 & p.Q556_V559delinsH; c.1668_1676del9/KIT11 & Stomach & overtly malignant & $\checkmark$ & $\checkmark$ \\
\hline X55KIT11 & p.W557_K558del/KIT11 & Stomach & intermediate & $\checkmark$ & \\
\hline X64KIT11 & p.V560D/KIT11 & Stomach & high & $\checkmark$ & $\checkmark$ \\
\hline X78KIT11 & p.W557_K558del; c.1669_1674del/KIT11 & Stomach & overtly malignant & $\checkmark$ & $\checkmark$ \\
\hline X82KIT11 & p.W557_P573delinsFQ/KIT11 & Stomach & overtly malignant & $\checkmark$ & \\
\hline X86KIT9 & p.A502_Y503dup/KIT9 & Small intestine & overtly malignant & $\checkmark$ & \\
\hline
\end{tabular}


Table 1. Cont.

\begin{tabular}{|c|c|c|c|c|c|c|}
\hline \multicolumn{7}{|c|}{ Gastrointestinal Stromal Tumors Imatinib-Naïve (IM-n) } \\
\hline Male & $\mathrm{n}=23$ & & & & & \\
\hline Female & $\mathrm{n}=10$ & & & & & \\
\hline Median age (range) & $65(41-85)$ & & & & & \\
\hline Sample code & KIT mutation status & & Location & Risk of malignancy * & miRNA & mRNA \\
\hline X89KIT17 & p.N822K/KIT17 & & Small intestine & overtly malignant & $\checkmark$ & $\checkmark$ \\
\hline X95KIT11 & p.T574_R586insK/KIT11 & & Stomach & intermediate & $\checkmark$ & \\
\hline X100KIT9 & p.A502_Y503dup/KIT9 & & Small intestine & overtly malignant & $\checkmark$ & \\
\hline X101KIT11 & p.E554_K558del/KIT11 & & Stomach & low & $\checkmark$ & \\
\hline X102KIT11 & p.W557R/KIT11 & & Stomach & high & $\checkmark$ & $\checkmark$ \\
\hline X108KIT9 & p.A502_Y503dup/KIT9 & & Small intestine & overtly malignant & $\checkmark$ & $\checkmark$ \\
\hline X.KIT11 & p.M552_E554delinsK/KIT11 & & Small intestine & overtly malignant & $\checkmark$ & \\
\hline X119KIT11 & p.Q556_I563del/KIT11 & & Stomach & low & $\checkmark$ & \\
\hline \multicolumn{7}{|c|}{ Gastrointestinal Stromal Tumors Imatinib-Resistant (IM-r) ${ }^{* * * *}$} \\
\hline Male & $\mathrm{n}=14$ & & & & & \\
\hline Female & $\mathrm{n}=6$ & & & & & \\
\hline Median age (range) & $49.5(22-67)$ & & & & & \\
\hline Sample code & KIT mutation status & KIT secondary mutation & Location & Risk of malignancy * & miRNA & mRNA \\
\hline Х2KIT9 & p.A502_Y503dup/KIT9 & Not detected & Colon & overtly malignant & $\checkmark$ & $\checkmark$ \\
\hline X27KIT11 & $\begin{array}{l}\text { p.L576P; c.1727 } \\
\text { T > C/27KIT11 }\end{array}$ & p.D820Y; c.2458G > T & Small intestine & overtly malignant & $\checkmark$ & $\checkmark$ \\
\hline X36KIT11 & p.Q556_E561delinsQ/KIT11 & Not detected & Small intestine & overtly malignant & $\checkmark$ & $\checkmark$ \\
\hline X42KIT9 & p.A502_Y503dup/KIT9 & KIT: p.V654A & Small intestine & overtly malignant & $\checkmark$ & $\checkmark$ \\
\hline X44KIT9 & p.A502_Y503dup/KIT9 & Not detected & Small intestine & overtly malignant & $\checkmark$ & $\checkmark$ \\
\hline X54KIT11 & p.K550_K558delinsQ/KIT11 & KIT: p.D820Y & Small intestine & overtly malignant & $\checkmark$ & $\checkmark$ \\
\hline X58KIT11 & p.I563_Q575del/KIT11 & KIT: p.D820Y & Stomach & overtly malignant & $\checkmark$ & $\checkmark$ \\
\hline X70KIT11 & p.E554_D572del/KIT11 & KIT: p.V654A & Small intestine & overtly malignant & $\checkmark$ & $\checkmark$ \\
\hline X71KIT11 & p.V559D/KIT11 & KIT: p.D820G & Small intestine & overtly malignant & $\checkmark$ & $\checkmark$ \\
\hline X73KIT11 & p.N567_L576delinsI/KIT11 & Not detected & Small intestine & overtly malignant & $\checkmark$ & $\checkmark$ \\
\hline X74KIT9 & p.A502_Y503dup/KIT9 & Not detected & Small intestine & overtly malignant & $\checkmark$ & \\
\hline X77KIT9 & p.A502_Y503dup/KIT9 & Not detected & Small intestine & overtly malignant & $\checkmark$ & $\checkmark$ \\
\hline
\end{tabular}


Table 1. Cont.

\begin{tabular}{|c|c|c|c|c|c|c|}
\hline \multicolumn{7}{|c|}{ Gastrointestinal Stromal Tumors Imatinib-Resistant (IM-r) ${ }^{* * *}$} \\
\hline Male & $\mathrm{n}=14$ & & & & & \\
\hline Female & $\mathrm{n}=6$ & & & & & \\
\hline Median age (range) & $49.5(22-67)$ & & & & & \\
\hline Sample code & KIT mutation status & KIT secondary mutation & Location & Risk of malignancy * & miRNA & mRNA \\
\hline X85KIT9 & p.A502_Y503dup/KIT9 & Not detected & Small intestine & overtly malignant & $\checkmark$ & $\checkmark$ \\
\hline X91KIT11 & p.K550_K558del/KIT11 & KIT: p.D820Y & Small intestine & overtly malignant & $\checkmark$ & \\
\hline X104KIT11 & p.W557_K558del/KIT11 & Not detected & Small intestine & overtly malignant & $\checkmark$ & $\checkmark$ \\
\hline X105KIT9 & p.A502_Y503dup/KIT9 & Not detected & Small intestine & overtly malignant & $\checkmark$ & $\checkmark$ \\
\hline X112KIT11 & $\begin{array}{l}\text { c.1654_1671del18 } \\
\text { (p.M552_W557del)/KIT11 }\end{array}$ & Not detected & Small intestine & overtly malignant & $\checkmark$ & $\checkmark$ \\
\hline X116KIT11 & p.557_558del homo/KIT11 & Not detected & Small intestine & overtly malignant & $\checkmark$ & \\
\hline X117KIT11 & $\begin{array}{l}\text { p.K550_V555delinsL; } \\
\text { c.1648_1663delinsT/KIT11 }\end{array}$ & p.D820Y; c.2458 G > T & Small intestine & overtly malignant & $\checkmark$ & \\
\hline X118KIT11 & $\begin{array}{l}\text { p.V559D; c.1676 } \\
\text { T > A/KIT11 }\end{array}$ & KIT p.V654A; c.1961 T > C & Small intestine & overtly malignant & $\checkmark$ & \\
\hline
\end{tabular}

* Tumor risk assessment was performed using AFiP criteria (Miettinen M. \& Lasota, J. Semin. Diagn. Pathol. 2006, 23, 70-83); ${ }^{* *}$ Recurrent or metastatic disease during clinical follow-up; *** Patients were only treated with imatinib, progression occurred after 6 months. 


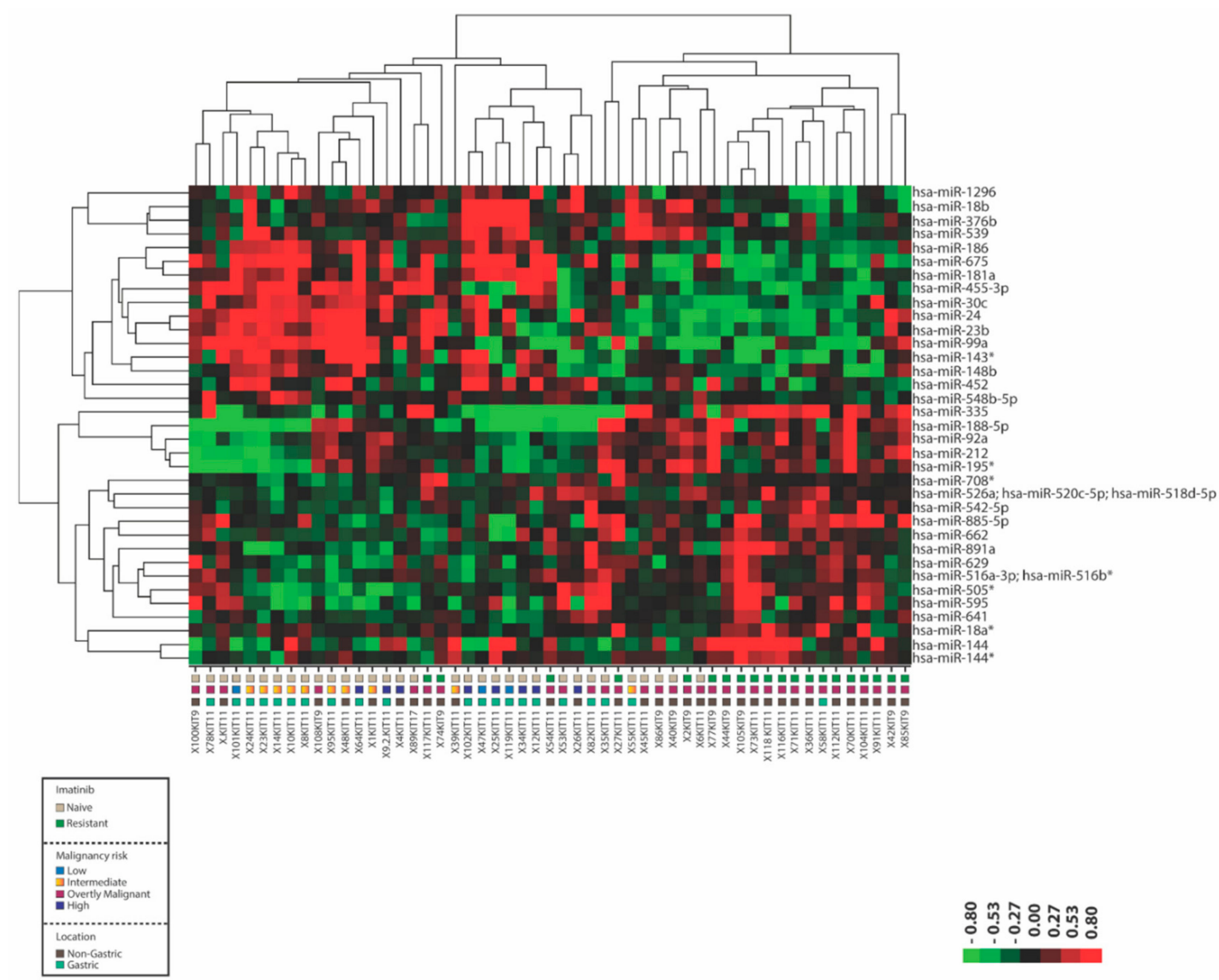

Figure 1. MicroRNA expression distinguishes imatinib-naïve (IM-n) from imatinib-resistant (IM-r) gastrointestinal stromal tumors (GIST). Fresh frozen tumor samples of IM-n and IM-r GIST patients were subjected to miRNA expression profiling. Depicted is the heat map of a supervised hierarchical clustering based on the 35 most significant $(p<0.01$ and False Discovery Rate (FDR) $<20 \%$ ) differentially expressed miRNAs. In the heat map red indicates relative high expression and green indicates relative low expression. The colored squares beneath the graph designate IM-n and IM-r samples, the malignancy risk and location of the tumors. Note that the sample codes below also indicate which KIT exon is mutated.

2.2. mRNA Expression Profiling and Ingenuity Pathway Analyses Reveal Differentially Expressed Genes and Pathways in Imatinib-Naïve and Imatinib-Resistant GIST Samples

In order to better understand the genes and molecular pathways involved in imatinib resistance in GIST we performed mRNA expression analyses on a subset (IM-r, $\mathrm{n}=15$ vs IM-n, $\mathrm{n}=14$ ) of our GIST samples. At least 352 genes were identified to be significantly differentially expressed $(p<0.008$, FDR $<10 \%$ ) between the two groups (Figure S1; Table S3). Figure 3 shows the cluster tree of a supervised cluster analysis based on the expression of the 352 differentially expressed genes represented by 475 different Affymetrix probe sets (Affymetrix, Santa Clara, CA, USA) (Figure S1). All IM-r samples cluster together as do all IM-n samples except one. A molecular pathway analysis, focusing on canonical pathways and using the Ingenuity platform (Qiagen, Hilden, Germany), was performed with the 352 differentially expressed genes as input. Among these genes, regulators of estrogen-mediated S-phase entry $\left(p=8.29 \times 10^{-8}\right)$, cyclins and cell cycle regulators $\left(p=3.09 \times 10^{-6}\right)$, as well as checkpoint regulators of G2/M DNA damage $\left(p=8.64 \times 10^{-6}\right)$ were overrepresented (Figure S2). Of note, the cyclins A2, B1, B2, D2, and E2, as well as CDK1 and the E2F transcription factors E2F7 and E2F8 were among the most differentially expressed genes found in two or more deregulated pathways (Table S4). Except for CCND2 (5.4 fold lower in IM-r), all the other seven genes displayed 
increased expression in IM-r with the fold changes of 2.6 for CCNA2, 2.9 for CCNE2, 2.3 for CCNB1, 2.1 for $C C N B 2,3.0$ for $C D K 1,2.1$ for $E 2 F 7$, and 2.0 for E2F8 in comparison to the imatinib-naïve setting.

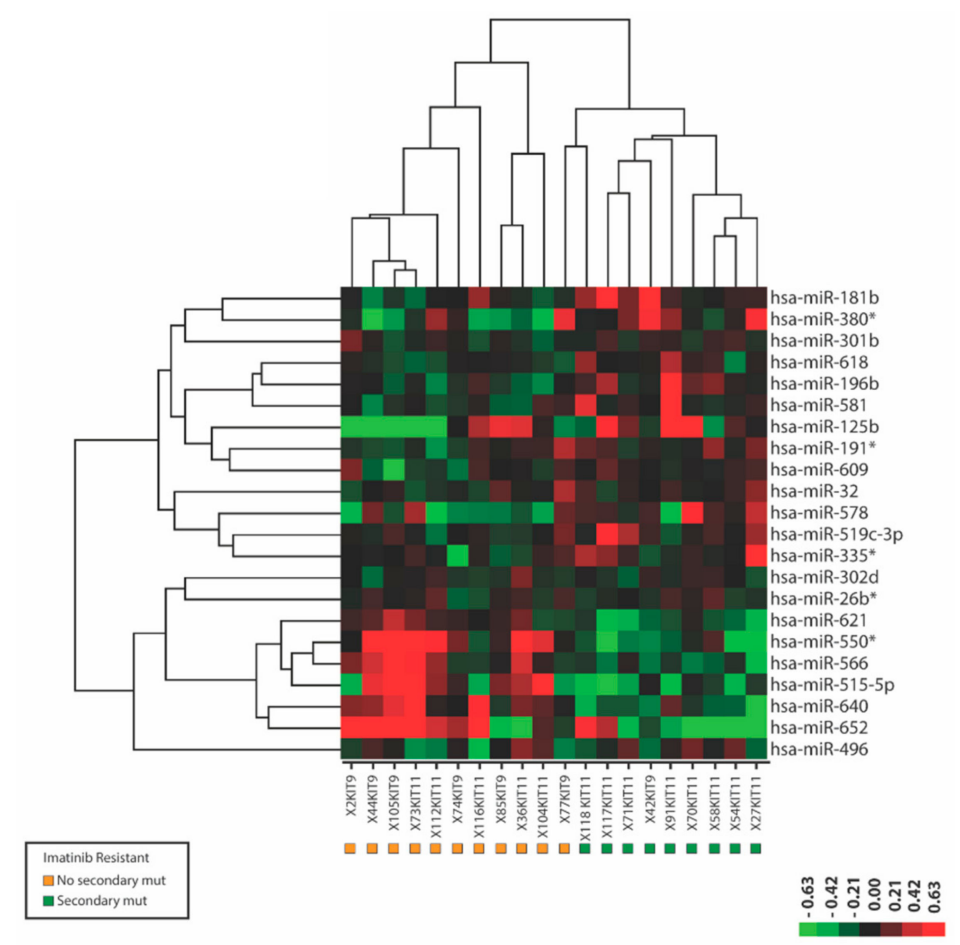

Figure 2. MicroRNAs differentially expressed between imatinib-resistant gastrointestinal stromal tumor (GIST) samples with and without secondary mutations in KIT. Depicted is a heat map of a supervised hierarchical clustering based on the 22 most significant $(p<0.01)$ differentially expressed miRNAs in fresh frozen GIST samples with (green squares) and without (orange squares) secondary imatinib resistance causing mutations in KIT. In the heat map red indicates relative high expression and green indicates relative low expression. Note that the sample codes below also indicate which KIT exon is mutated.

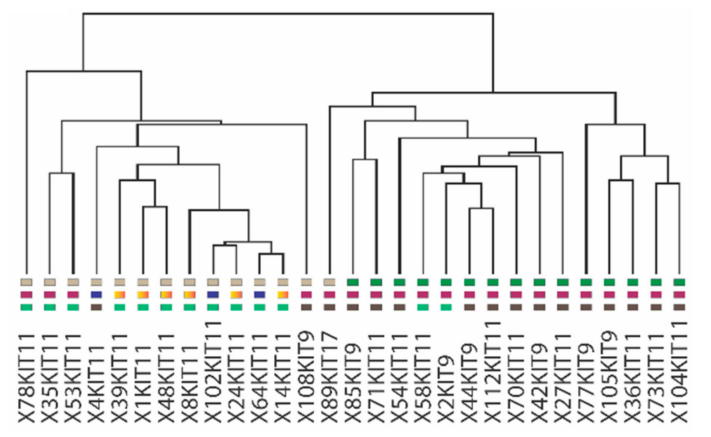

Figure 3. Supervised hierarchical clustering based on differential gene expression discriminates imatinib-naïve (IM-n) and imatinib-resistant (IM-r) gastrointestinal stromal tumor (GIST) samples. Transcript expression profiles were determined using the Affymetrix platform (U133 plus 2) of 29 fresh frozen samples derived of IM-n $(n=14)$ and IM-r $(n=15)$ GISTs. Depicted is the cluster tree of a supervised hierarchical clustering based on 352 significant $(p<0.008$, False Discovery Rate (FDR) $<10 \%)$, differentially expressed transcripts. Note that $100 \%$ of the IM-r samples are clustered together with a single IM-n GIST sample. The colored squares beneath the graph designate imatinib-naïve and imatinib-resistant samples, the malignancy risk and location of the tumors (see Figure 1). Note that the sample codes below also indicate which KIT exon is mutated. 
An ingenuity pathway analysis (IPA) was also conducted to examine interactions within the 352 most differentially expressed genes between IM-r and IM-n GIST samples. Figure 4A,B depict two of the largest and most significant interaction networks revealed by IPA (see for a symbol legend Table S5). Figure 4A displays associations between genes involved in cell cycle regulation and consequently cell proliferation. Cyclin A and cyclin E appear as central hubs in the gene network. The interaction network shown in Figure 4B also supports cell cycling and cell proliferation judged by the overexpressed central genes cyclin dependent kinase 1 (CDK1), aurora kinase B (AURKB), and forkhead box protein M1 (FOXM1). CDK1 plays a key role in cell cycle regulation, AURKB regulates the segregation of chromosomes and the spindle checkpoint in mitosis and FOXM1 is a transcription factor essential for cell cycle regulation.

\subsection{Integration of Differentially Expressed microRNAs and mRNAs into Networks}

Using IPA, we investigated whether interaction networks between mRNAs and miRNAs could be defined to identify and better understand the possible regulatory role of miRNAs-mRNAs interactions in imatinib resistance. To be able to directly compare mRNA with miRNA expression in the same GIST samples, we considered only the differentially expressed miRNAs in the subset of GIST samples that were analyzed by mRNA expression profiling. We identified 88 differentially expressed miRNAs $(p<0.03, \mathrm{FDR}<30 \%)$ (Table S6). Note that almost $70 \%$ of the differentially miRNAs reported in Figure 1 and Table $\mathrm{S} 1$ were present in this miRNA selection.

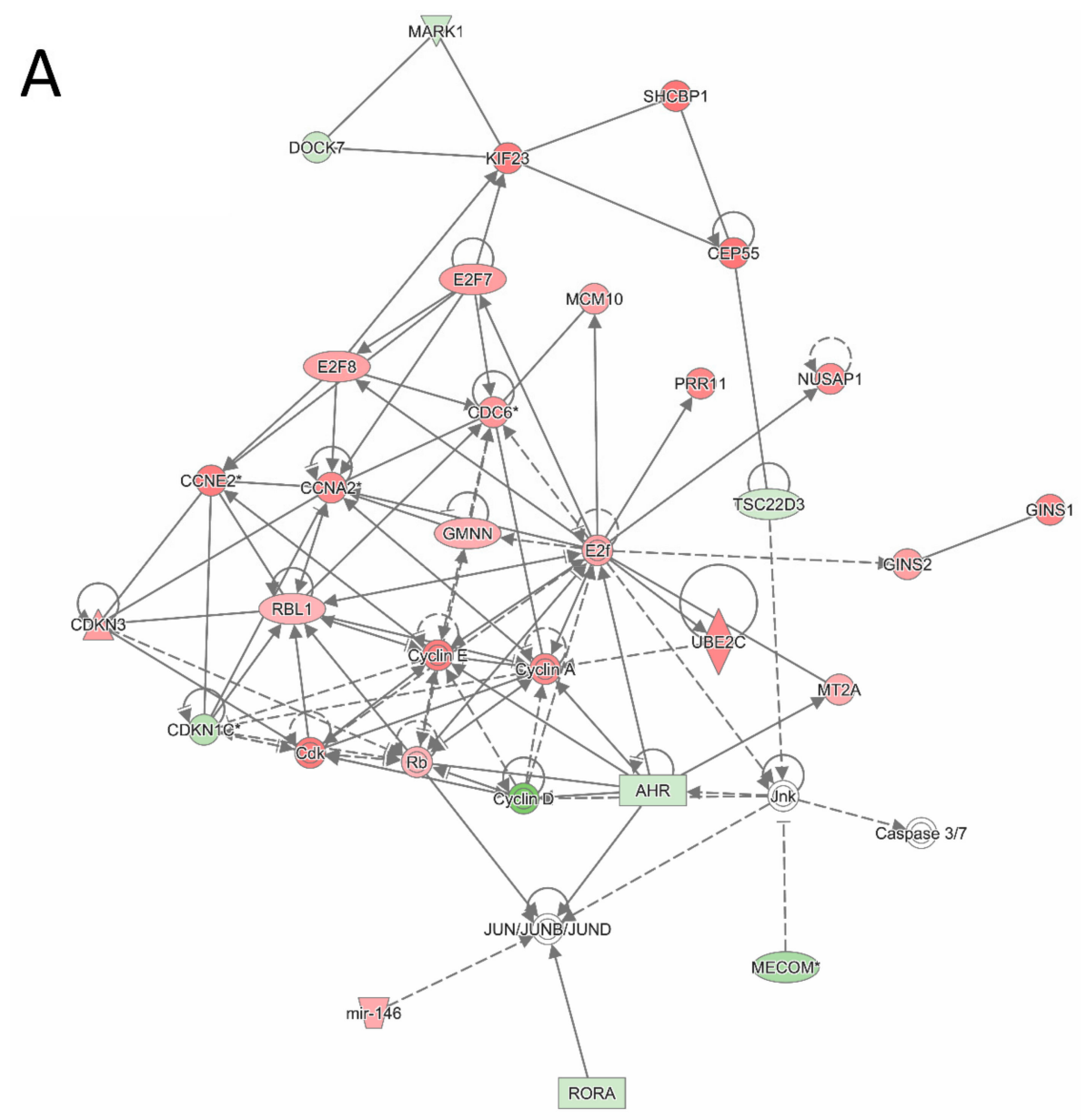

Figure 4. Cont. 

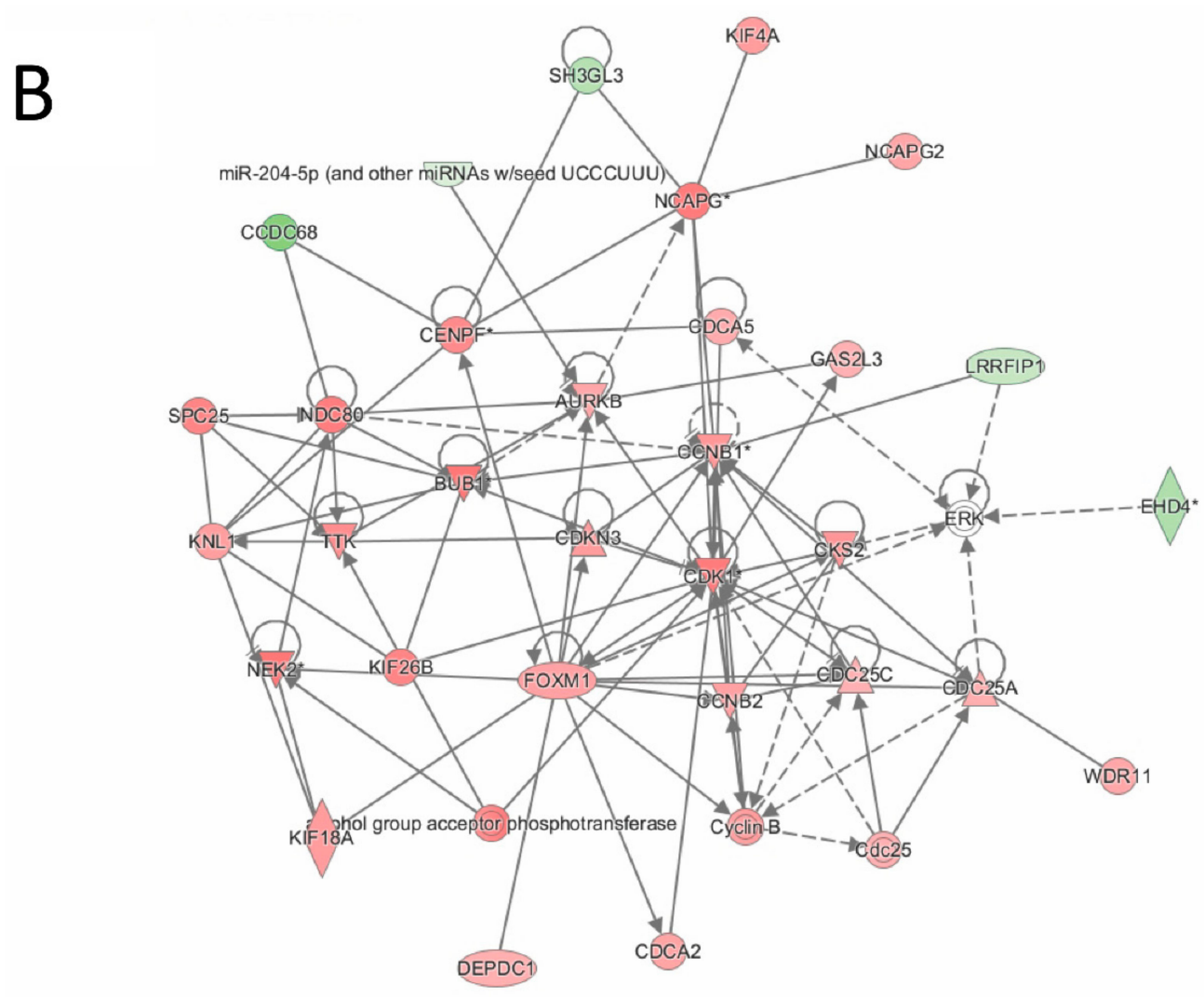

Figure 4. Ingenuity Pathway Analysis indicates the relation between genes differentially expressed between imatinib-naïve (IM-n) and imatinib-resistant (IM-r) gastrointestinal stromal tumor (GIST) samples. The 352 significant differentially expressed genes between IM-r and IM-n GIST samples were used as input for an Ingenuity Pathway Analysis (IPA). The depicted IPA networks illustrate and visualize associations between the genes. (A) IPA network highlighting cell cycle related, differentially expressed genes. (B) IPA network highlighting CDK1, AURKB, and FOXM1 interactions. Green and red shading indicates relatively low and high expression in the IM-r samples. See Table S5 for an extended symbol legend.

The gene-miRNA network presented in Figure 5 included most regulatory gene-miRNA interactions and related to cell cycle regulation. The network highlights regulation by miR-92a-3p, miR-99a-5p, and miR-101-3p. The differential expression of selected miRNAs and mRNAs, which were indicated in the text and IPA analyses, were verified by RT-PCR, thereby confirming our findings with the miRNA and mRNA array platforms (Figure S3).

\section{Discussion}

To better understand the mechanisms that account for imatinib resistance, here we molecularly characterized at an mRNA and miRNA level a unique set of IM-n and IM-r GIST samples. Bioinformatic approaches were used to identify signaling pathways and gene networks modulated in imatinib-resistant GISTs. 


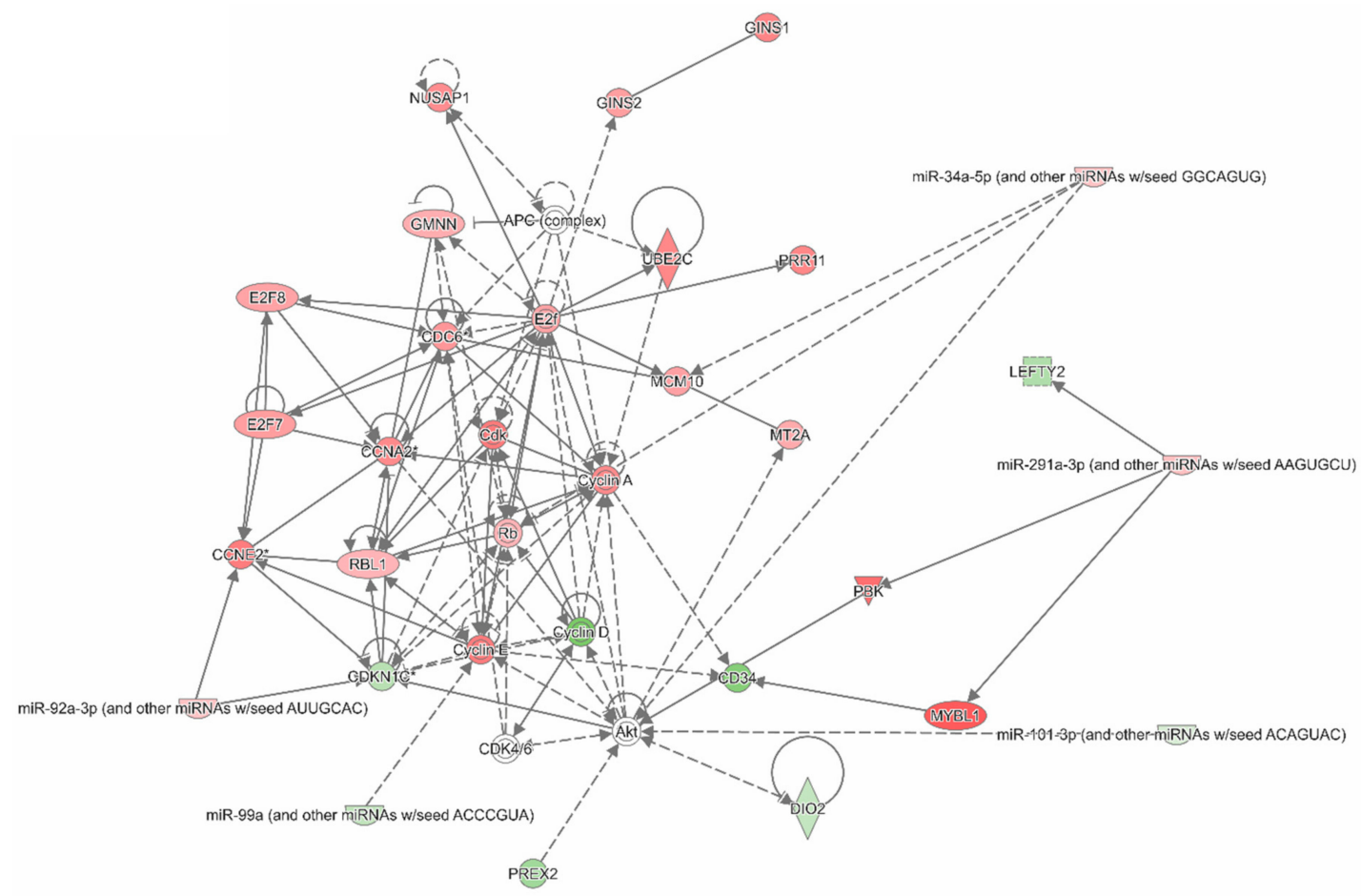

Figure 5. Ingenuity Pathway Analysis integrating differentially expressed genes and microRNAs between imatinib-naïve (IM-n) and imatinib-resistant (IM-r) gastrointestinal stromal tumor (GIST) samples. As input for an Ingenuity Pathway Analysis (IPA) the significantly differentially expressed transcripts (352 genes, $p<0.008$, False Discovery Rate (FDR) $<10 \%$ ) and miRNAs (88 miRNAs, $p<0.03$, FDR $<30 \%)$ from the same set of IM-r $(n=15)$ and IM-n $(n=14)$ GIST samples were used. The depicted network indicates miRNA-gene interactions relevant in context of the cell cycle. Green and red shading indicates relatively low and high expression in the IM-r samples. See Table S5 for an extended symbol legend.

The reason to look for differentially expressed miRNAs between IM-n and IM-r samples is based on the observations that miRNAs are intimately involved in GIST pathobiology $[18,19]$ and well-known actors in drug resistance mechanisms occurring in cancer types other than GIST [20]. Indeed, we identified miRNAs that distinguished IM-r from IM-n GIST samples. Although the fold changes observed were relatively small, they can still have a significant impact on protein levels because the regulation of multiple targets within the same pathway can amplify their biological effect [21] and different miRNAs may cooperate and have synergistic effects [22]. Previously few other groups studied miRNA expression in relation to imatinib-resistance in GIST as well $[23,24]$. Akaçakaya et al. compared miRNA expression profiles of 17 GISTs of which 10 responded to imatinib (imatinib-sensitive) and seven progressed on imatinib (imatinib-resistant) [23]. They identified ten differentially expressed miRNAs a.o. miR-125a-5p that were found to be overexpressed in IM-r GIST and of which the expression was inversely correlated to levels of protein tyrosine phosphatase, non-receptor Type18 (PTPN18) [23]. The lowered PTPN18 levels conferred imatinib resistance in GIST822 cells. In a recent follow-up paper evidence was provided that the miR-125a-5p and PTPN18 effects on imatinib resistance were mediated through phosphorylated FAK levels [25]. Shi et al., reported downregulation of miR-518a-5p in IM-r that targets PIK3C2A [24]. Unfortunately, PIK3C2A levels were not modulated to validate its levels affecting imatinib sensitivity in GIST cells. Similarly, no evidence for an inverse correlation between miR-518a-5p and PIK3C2A expression in clinical samples was presented. The overlap in miRNAs detected between these studies and ours is limited, most likely due to different experimental set-ups, including the exact nature and number of GIST samples analyzed and the use of different miRNA detection platforms. In chronic myeloid leukemia (CML), another malignancy that is treated with imatinib, miRNAs have also been linked to imatinib resistance [26-28]. A number of miRNAs, e.g., 
miR-99a, miR-30c, and miR-101, which were all found downregulated in the IM-r samples (Table S6), have been previously associated with imatinib resistance in GIST or chronic myeloid leukemia [26,27]. The observed downregulation of miR-30c and miR-181a in our IM-r samples corresponded to findings in CML in which lowered expression of these miRNAs was also found in imatinib resistant cells $[27,28]$. In most cases dysregulated miRNAs in the IM-r setting were not further functionally characterized to substantiate their roles and involvement in imatinib resistance.

Interestingly, the miRNA expression profiles were able to distinguish IM-r GIST samples with and without secondary KIT mutations. This observation may reflect a different biology underlying the resistance phenotype in the two groups. However, the accompanying fold differences in miRNA expression are small. To verify our findings larger sample cohorts should be examined using an RT-PCR platform.

Pathway and network analyses using differentially expressed transcripts and mRNAs as input indicated the upregulation of multiple cell-cycle related genes in the IM-r GIST samples. The cyclins A and $\mathrm{E}$ are well-known regulators of G1/S, S, and G2/M transition phases. Their increased expression levels, as well as those of most other genes in the network, most likely facilitates cell cycling and consequently cell proliferation. In this context the reduced expression of cyclin dependent kinase inhibitor $1 \mathrm{C}(C D K N 1 C)$, a negative regulator of cell proliferation, also makes sense. However, the reduced expression of cyclin D2 (CCND2) does not seem to fit as its expression was found downregulated in the IM-r samples. It is unclear to what extent these findings are merely a reflection of the progressive nature of the IM-r GISTs. Aberrant expression of the majority of these genes is known to be involved in drug-resistance in various cancer types [29-31]. Of interest is the increased expression of the atypical E2F transcription factor family members E2F7 and E2F8. The precise function of these E2F family members in GIST and other cancers is still ill-defined. E2F7 overexpression has been linked to tamoxifen and anthracycline resistance in breast cancer and head and neck squamous cell carcinoma, respectively [32,33]. E2F8 promotes cell proliferation and tumorigenicity in breast cancer [34] and cisplatin resistance to estrogen receptor positive breast cancer cells [35]. The increased cell cycle activity may render IM-r GIST sensitive to cell cycle inhibitors.

The other highlighted gene interaction network is also conducive of cell cycle progression. This network points to central roles for AURKB and FOXM1 of which the expression was increased in IM-r GISTs. AURKB, together with AURKA, which is also upregulated in IM-r samples (Table S3), are serine/threonine kinases that regulate mitosis. These genes are found upregulated in many cancers and targeted inhibitors have been developed [36]. In GIST AURKA expression has been identified as a negative prognostic factor $[37,38]$ and has recently been implicated as a therapeutic target [39]. The significance of FOXM1 in GIST was recently emphasized by reporting its role in GIST progression [40]. Furthermore the FOXO3a-FOXM1 axis has been implicated in cancer related processes like proliferation, survival, drug resistance, angiogenesis, migration, and DNA repair in other cancers [41]. Perhaps FOXM1 overexpression can be therapeutically exploited, e.g., by using thiazole antibiotics.

The integrative network analyses implicated some of the differentially expressed miRNAs as regulators of cell cycle related genes. Of special interest is miR-92a-3p, which is predicted to target CDKN1C through a highly conserved binding site in its 3'UTR, as predicted by TargetScan v7.2 (http://www.targetscan.org). The downregulation of miR-99a-5p affects mTOR levels [42,43]. The upregulation of mTOR stimulates cell cycle progression through its cell growth effectors S6K1 and eIF4E [44]. Finally, miR-101-3p has been implicated in imatinib sensitivity in CML with high levels sensitizing to imatinib through the downregulation of JAK2 and inhibition of NF- $\mathrm{kB}$ target genes [26]. So conversely miR-101-3p downregulation might cause imatinib resistance. Furthermore miR-101-3p regulates the PI3K/AKT/mTOR pathway $[45,46]$ mediating AKT activation, which may reduce CDKN1C levels [47].

Our findings demonstrated that IM-r GIST samples can be distinguished from IM-n GIST samples based on their miRNA and mRNA expression profiles. In addition, we identified several miRNAs 
that discriminated between IM-r GIST samples with or without secondary KIT mutations. Pathway and network analyses highlighted cell cycle related genes/gene networks in IM-r GISTs and identified overexpressed proteins that may be pharmacologically targeted using small molecule inhibitors. Further, our data implicated at least three miRNAs, miR-92a-3p, miR-99a-5p, and miR-101-3p, as potential effectors of imatinib resistance. Future experimental in vitro and in vivo studies are needed to further substantiate and validate these findings.

\section{Materials and Methods}

\subsection{Patient Samples}

Fresh frozen GIST samples $(n=53)$ were obtained from the tissue bank of the Department of Pathology of the University Hospitals Leuven, Belgium and the Department of Soft Tissue/Bone Sarcoma and Melanoma, Marie Skłodowska-Curie Institute, Oncology Center, Warsaw, Poland. The initial GIST diagnosis was based on histological features as assessed by an expert pathologist, immunostaining for CD117/KIT and anoctamin (ANO1 or DOG1), and the presence of KIT mutations. All tumor samples that were analyzed contained $>80 \%$ tumor cells, contained KIT activating mutations, and were derived from both IM-n $(n=33)$ and IM-r $(n=20)$ GISTs. The pathological and initial diagnostic molecular evaluation were all performed in a single institution (KU Leuven). Clinicopathological characteristics concerning patients and tumors are listed in Table 1 . The majority of the patients from whom the GIST samples were derived were diagnosed and treated from 2000 to 2011 according to the applicable guidelines in that time-period. All patients consented to use their tissues for research purposes and approval was obtained from the Ethics Committee of the University Hospitals Leuven (ML7481) and the Oncology Center, Warsaw, Poland. The study was carried out in the context of a research protocol "Translational research in soft tissue sarcomas", which was reviewed and approved by the Medical Ethical Review board of the Erasmus Medical Center (MEC-2016-213) on 11th April 2016. The study was performed in accordance with the Declaration of Helsinki.

\subsection{RNA Isolation and microRNA Profiling}

Total RNA was isolated from fresh frozen tumor samples using RNAbee (Tel Test Inc., Friendswood, TX, USA) following the standard extraction protocol recommended by the manufacturer. RNA concentration and quality were examined using a Nanodrop-1000 (Nanodrop Technologies, Wilmington, DE, USA). MiRNA expression profiles were determined using miRNA microarrays, essentially as described before by Pothof et al. [48]. In brief, using the Kreatech ULS ${ }^{\mathrm{TM}}$ aRNA labeling Kit (Kreatech Diagnostics/Leica Biosystems, Amsterdam, the Netherlands), $1 \mu \mathrm{g}$ total RNA was labeled with Cy3. The Cy3-tagged RNA was hybridized overnight to LNA ${ }^{\mathrm{TM}}$ modified oligonucleotide capture probes (Exiqon, Vedbaek, Denmark) spotted in duplicate on Nexterion E slides. Of the 1344 capture probes on the slides, 725 were specifically designed to detect human miRNAs. After hybridization, slides were scanned, and median spot intensity was determined using ImaGene software (BioDiscovery Inc., El Segundo, CA, USA). After background subtraction, expression values were Quantile normalized using R-software, bad spots were deleted, and duplicate spots averaged. The normalized miRNA expression data were $\log 2$ transformed and median centered to acquire the relative expression values that were used for hierarchical clustering analysis using the open source software Cluster 3.0 [49] and Java Tree View [50]. A two-sample t-test was used to determine statistical significance $(p<0.05)$ between imatinib-naïve and imatinib-resistant samples and the Benjamini-Hochberg false discovery rate (FDR) was used to control for multiple testing. The miRNA expression datasets generated and analyzed during the current study are presented in Table S7.

\section{3. $m R N A$ Expression Analysis}

Gene expression analysis using the Affymetrix HG-U133_Plus_2 platform was carried out according to standard operating procedures by the VIB MicroArray Facility of the KU Leuven. 
Raw. cel files were processed using fRMA parameters (median polish) after which batch effects were corrected using ComBat. [51,52]. BRB-Array tools (Biometric Research Branch Array Tools (http://brb.nci.nih.gov/BRB-ArrayTools/) was used for analyzing the transcript expression data and a two-sample t-test was used for statistical testing. The mRNA expression datasets generated and analyzed during the current study have been deposited to the Gene Expression Omnibus (GEO) data repository under accession number GSE132542.

\subsection{Quantitative RT-PCR}

The differential expression of selected miRNAs in IM- $n(n=33)$ and IM-r $(n=20)$ GIST samples, as detected by the LNA ${ }^{\mathrm{TM}}$ modified oligonucleotide platform, was validated by RT-PCR using the TaqMan ${ }^{\circledR}$ miRNA Assays Technology (Applied Biosystems/ThermoFisher Scientific, Bleiswijk, the Netherlands). In brief, total RNA (50 ng) was reverse transcribed in a multiplex reaction using specific miRNA primers from the TaqMan ${ }^{\circledR}$ miRNA Assays and reagents from the TaqMan ${ }^{\circledR}$ miRNA Reverse Transcription Kit (Applied Biosystems/ThermoFisher Scientific) according to the manufacturer's protocol. The resulting cDNA was used as input in a quantitative real-time PCR (qPCR) using a miRNA specific primer/probe mix together with the TaqMan ${ }^{\circledR}$ Universal PCR Master Mix No AmpErase ${ }^{\circledR}$ UNG (Applied Biosystems/ThermoFisher Scientific) using the 7500 Fast Real-Time PCR systems (Applied Biosystems). The qPCR data were analyzed using SDS software (version 2.4, Applied Biosystems/ThermoFisher Scientific). A standard dilution series of a cDNA sample-pool was included on every plate allowing for the absolute quantification of the miRNA expression.

The differential expression of selected mRNAs in IM- $n(n=33)$ and IM-r $(n=20)$ GIST samples, as detected by the Affymetrix platform, was validated by RT-PCR using the TaqMan ${ }^{\circledR}$ Technology (Applied Biosystems/ThermoFisher Scientific). In brief, total RNA $(1 \mu \mathrm{g})$ was used as input for a reverse transcription reaction using a high capacity cDNA reverse transcription kit (Applied Biosystems/ThermoFisher Scientific) according to procedures by the manufacturer. The cDNA was used in a PCR reaction using primer/probe combinations from the following Taqman ${ }^{\circledR}$ gene expression assays (AURKA, assay ID: Hs01582072_m1; AURKB, assay ID: Hs00945858_g1; CCND2, assay ID:Hs00153380_m1; CCNE2, assay ID: Hs00180319_m1; CDK1, assay ID: Hs00938777_m1;CDKN1C, assay ID: Hs00175938_m1; E2F7, assay ID: Hs00987777_m1; FOXM1, assay ID: Hs01073586_m1) and Taqman ${ }^{\circledR}$ Universal PCR master mix using the 7500 Fast Real-Time PCR system (all obtained from Applied Biosystems/ThermoFisher Scientific) according to the manufacturer's recommendations. Three housekeepers (GAPDH, HPRT, and PPIA) were used for normalization purposes using the comparative $\mathrm{C}_{\mathrm{T}}$-method. The $\mathrm{qPCR}$ data were analyzed using SDS software (version 2.4, Applied Biosystems/ThermoFisher Scientific).

\subsection{Pathway Analysis}

For pathway analyses, a commercial software application, Ingenuity ${ }^{\circledR}$ Pathway Analysis (IPA $\left.{ }^{\circledR}\right)$, was used. IPA calculates and visualizes the known pathway associations and interactions between sets of transcripts. mRNAs and/or miRNAs that were significantly differentially expressed between IM-n and IM-r samples were selected and accompanying identifiers and fold changes were uploaded into the IPA. The mRNA data were used to identify canonical signaling and metabolic pathways that were predicted to be activated or inhibited (canonical pathway analysis). The miRNA and mRNA data together were used to construct interaction networks, networks based on molecular relationships between differentially expressed mRNAs and/or miRNAs. These networks were matched to and derived from a "global molecular network" developed from the available online information in the IPA. The pathway and network analyses were performed using filtering of "Human" and "uncategorized" for species as well as "direct and indirect relationships" for general settings. The presented networks were representations of molecular relationships between mRNA-mRNA and miRNA-mRNA interactions.

Supplementary Materials: The following are available online at http://www.mdpi.com/2072-6694/11/6/882/s1: Table S1: Differentially expressed microRNAs between imatinib-naïve and imatinib-resistant gastrointestinal 
stromal tumors; Table S2: Differentially expressed microRNAs between imatinib-resistant gastrointestinal stromal tumors with and without secondary KIT mutations; Table S3: List of 352 differentially expressed genes between imatinib-resistant and imatinib-naïve GIST samples; Table S4: Differentially expressed genes associated with the top deregulated canonical pathways; Table S5: Ingenuity Pathway Analysis Symbols; Table S6: Differentially expressed microRNAs between imatinib-naïve and imatinib-resistant gastrointestinal stromal tumors in the samples that were used for mRNA profiling; Table S7: Overview of the microRNA expression levels measured in the imatinib-naïve and imatinib-resistant gastrointestinal stromal tumor samples; Figure S1: Differentially expressed mRNAs between imatinib-naïve and imatinib-resistant GIST samples; Figure S2: Top deregulated canonical pathways between imatinib-naïve and imatinib-resistant gastrointestinal stromal tumors; Figure S3: Quantitative RT-PCR validation of differentially expressed microRNAs and mRNAs in imatinib-naïve and imatinib-resistant gastrointestinal stromal tumors.

Author Contributions: Conceptualization: A.A., C.M.M.G., M.D.-R., S.S., and E.A.C.W.; methodology: A.A., C.M.M.G., P.F.v.K., M.S., A.L.M.V., M.D.-R., and E.A.C.W.; validation: A.A., C.M.M.G., P.F.v.K., M.S., and A.L.M.V.; formal analysis: A.A., M.S., and E.A.C.W.; investigation: A.A., C.M.M.G., P.F.v.K., M.S., A.L.M.V., M.D.-R., and E.A.C.W.; resources: P.R., R.S., P.S., and S.S.; data curation: A.A., C.M.M.G., P.F.v.K., M.S., A.L.M.V., M.D.-R., and E.A.C.W.; writing-original draft preparation: A.A., S.S., and E.A.C.W.; writing-review and editing: A.A., C.M.M.G., P.F.v.K., M.S., A.L.M.V., P.R., R.S., P.S., M.D.-R., S.S., and E.A.C.W.; supervision: S.S. and E.A.C.W.; project administration, S.S. and E.A.C.W.; funding acquisition: S.S. and E.A.C.W.

Funding: This research was funded by the EC FP6 CONTICANET network of excellence (LSHC-CT-2005-018806) from the European Commission and internal funds from the Department of Medical Oncology of the Erasmus MC.

Conflicts of Interest: The authors declare no conflict of interest. The funders had no role in the design of the study; in the collection, analyses, or interpretation of data; in the writing of the manuscript; or in the decision to publish the results.

\section{References}

1. Kindblom, L.G.; Remotti, H.E.; Aldenborg, F.; Meis-Kindblom, J.M. Gastrointestinal pacemaker cell tumor (gipact): Gastrointestinal stromal tumors show phenotypic characteristics of the interstitial cells of cajal. Am. J. Pathol. 1998, 152, 1259-1269. [PubMed]

2. Heinrich, M.C.; Corless, C.L.; Demetri, G.D.; Blanke, C.D.; von Mehren, M.; Joensuu, H.; McGreevey, L.S.; Chen, C.J.; Van den Abbeele, A.D.; Druker, B.J.; et al. Kinase mutations and imatinib response in patients with metastatic gastrointestinal stromal tumor. J. Clin. Oncol. 2003, 21, 4342-4349. [CrossRef]

3. Hirota, S.; Isozaki, K.; Moriyama, Y.; Hashimoto, K.; Nishida, T.; Ishiguro, S.; Kawano, K.; Hanada, M.; Kurata, A.; Takeda, M.; et al. Gain-of-function mutations of c-kit in human gastrointestinal stromal tumors. Science 1998, 279, 577-580. [CrossRef]

4. Ricci, R.; Dei Tos, A.P.; Rindi, G. Gistogram: A graphic presentation of the growing gist complexity. Virchows Arch. 2013, 463, 481-487. [CrossRef] [PubMed]

5. Corless, C.L.; Barnett, C.M.; Heinrich, M.C. Gastrointestinal stromal tumours: Origin and molecular oncology. Nat. Rev. Cancer 2011, 11, 865-878. [CrossRef] [PubMed]

6. Blanke, C.D.; Demetri, G.D.; von Mehren, M.; Heinrich, M.C.; Eisenberg, B.; Fletcher, J.A.; Corless, C.L.; Fletcher, C.D.; Roberts, P.J.; Heinz, D.; et al. Long-term results from a randomized phase ii trial of standardversus higher-dose imatinib mesylate for patients with unresectable or metastatic gastrointestinal stromal tumors expressing kit. J. Clin. Oncol. 2008, 26, 620-625. [CrossRef] [PubMed]

7. Verweij, J.; Casali, P.G.; Zalcberg, J.; LeCesne, A.; Reichardt, P.; Blay, J.Y.; Issels, R.; van Oosterom, A.; Hogendoorn, P.C.; Van Glabbeke, M.; et al. Progression-free survival in gastrointestinal stromal tumours with high-dose imatinib: Randomised trial. Lancet 2004, 364, 1127-1134. [CrossRef]

8. Casali, P.G.; Zalcberg, J.; Le Cesne, A.; Reichardt, P.; Blay, J.Y.; Lindner, L.H.; Judson, I.R.; Schoffski, P.; Leyvraz, S.; Italiano, A.; et al. Ten-year progression-free and overall survival in patients with unresectable or metastatic gi stromal tumors: Long-term analysis of the european organisation for research and treatment of cancer, italian sarcoma group, and australasian gastrointestinal trials group intergroup phase iii randomized trial on imatinib at two dose levels. J. Clin. Oncol. 2017, 35, 1713-1720.

9. Debiec-Rychter, M.; Sciot, R.; Le Cesne, A.; Schlemmer, M.; Hohenberger, P.; van Oosterom, A.T.; Blay, J.Y.; Leyvraz, S.; Stul, M.; Casali, P.G.; et al. Kit mutations and dose selection for imatinib in patients with advanced gastrointestinal stromal tumours. Eur. J. Cancer 2006, 42, 1093-1103. [CrossRef] 
10. Antonescu, C.R.; Besmer, P.; Guo, T.; Arkun, K.; Hom, G.; Koryotowski, B.; Leversha, M.A.; Jeffrey, P.D.; Desantis, D.; Singer, S.; et al. Acquired resistance to imatinib in gastrointestinal stromal tumor occurs through secondary gene mutation. Clin. Cancer Res. 2005, 11, 4182-4190. [CrossRef]

11. Debiec-Rychter, M.; Cools, J.; Dumez, H.; Sciot, R.; Stul, M.; Mentens, N.; Vranckx, H.; Wasag, B.; Prenen, H.; Roesel, J.; et al. Mechanisms of resistance to imatinib mesylate in gastrointestinal stromal tumors and activity of the pkc412 inhibitor against imatinib-resistant mutants. Gastroenterology 2005, 128, 270-279. [CrossRef] [PubMed]

12. Heinrich, M.C.; Corless, C.L.; Blanke, C.D.; Demetri, G.D.; Joensuu, H.; Roberts, P.J.; Eisenberg, B.L.; von Mehren, M.; Fletcher, C.D.; Sandau, K.; et al. Molecular correlates of imatinib resistance in gastrointestinal stromal tumors. J. Clin. Oncol. 2006, 24, 4764-4774. [CrossRef]

13. Liegl, B.; Kepten, I.; Le, C.; Zhu, M.; Demetri, G.D.; Heinrich, M.C.; Fletcher, C.D.; Corless, C.L.; Fletcher, J.A. Heterogeneity of kinase inhibitor resistance mechanisms in gist. J. Pathol. 2008, 216, 64-74. [CrossRef] [PubMed]

14. Wardelmann, E.; Merkelbach-Bruse, S.; Pauls, K.; Thomas, N.; Schildhaus, H.U.; Heinicke, T.; Speidel, N.; Pietsch, T.; Buettner, R.; Pink, D.; et al. Polyclonal evolution of multiple secondary kit mutations in gastrointestinal stromal tumors under treatment with imatinib mesylate. Clin. Cancer Res. 2006, 12, 1743-1749. [CrossRef]

15. Mahadevan, D.; Cooke, L.; Riley, C.; Swart, R.; Simons, B.; Della Croce, K.; Wisner, L.; Iorio, M.; Shakalya, K.; Garewal, H. A novel tyrosine kinase switch is a mechanism of imatinib resistance in gastrointestinal stromal tumors. Oncogene 2007, 26, 3909-3919. [CrossRef] [PubMed]

16. Sakurama, K.; Noma, K.; Takaoka, M.; Tomono, Y.; Watanabe, N.; Hatakeyama, S.; Ohmori, O.; Hirota, S.; Motoki, T.; Shirakawa, Y.; et al. Inhibition of focal adhesion kinase as a potential therapeutic strategy for imatinib-resistant gastrointestinal stromal tumor. Mol. Cancer Ther. 2009, 8, 127-134. [CrossRef]

17. Takahashi, T.; Serada, S.; Ako, M.; Fujimoto, M.; Miyazaki, Y.; Nakatsuka, R.; Ikezoe, T.; Yokoyama, A.; Taguchi, T.; Shimada, K.; et al. New findings of kinase switching in gastrointestinal stromal tumor under imatinib using phosphoproteomic analysis. Int. J. Cancer 2013, 133, 2737-2743. [CrossRef]

18. Gits, C.M.; van Kuijk, P.F.; Jonkers, M.B.; Boersma, A.W.; van IJcken, W.F.; Wozniak, A.; Sciot, R.; Rutkowski, P.; Schoffski, P.; Taguchi, T.; et al. Mir-17-92 and mir-221/222 cluster members target kit and etv1 in human gastrointestinal stromal tumours. Br. J. Cancer 2013, 109, 1625-1635. [CrossRef]

19. Yun, S.; Kim, W.K.; Kwon, Y.; Jang, M.; Bauer, S.; Kim, H. Survivin is a novel transcription regulator of kit and is downregulated by mirna-494 in gastrointestinal stromal tumors. Int. J. Cancer 2018, 142, 2080-2093. [CrossRef]

20. Fanini, F.; Fabbri, M. Micrornas and cancer resistance: A new molecular plot. Clin. Pharmacol. Ther. 2016, 99, 485-493. [CrossRef]

21. Calin, G.A.; Croce, C.M. Microrna-cancer connection: The beginning of a new tale. Cancer Res. 2006, 66, 7390-7394. [CrossRef]

22. Xu, J.; Li, C.X.; Li, Y.S.; Lv, J.Y.; Ma, Y.; Shao, T.T.; Xu, L.D.; Wang, Y.Y.; Du, L.; Zhang, Y.P.; et al. Mirna-mirna synergistic network: Construction via co-regulating functional modules and disease mirna topological features. Nucleic Acids Res. 2011, 39, 825-836. [CrossRef] [PubMed]

23. Akcakaya, P.; Caramuta, S.; Ahlen, J.; Ghaderi, M.; Berglund, E.; Ostman, A.; Branstrom, R.; Larsson, C.; Lui, W.O. Microrna expression signatures of gastrointestinal stromal tumours: Associations with imatinib resistance and patient outcome. Br. J. Cancer 2014, 111, 2091-2102. [CrossRef] [PubMed]

24. Shi, Y.; Gao, X.; Hu, Q.; Li, X.; Xu, J.; Lu, S.; Liu, Y.; Xu, C.; Jiang, D.; Lin, J.; et al. Pik3c2a is a gene-specific target of microrna-518a-5p in imatinib mesylate-resistant gastrointestinal stromal tumor. Lab. Investig. 2016, 96, 652-660. [CrossRef]

25. Huang, W.K.; Akcakaya, P.; Gangaev, A.; Lee, L.; Zeljic, K.; Hajeri, P.; Berglund, E.; Ghaderi, M.; Ahlen, J.; Branstrom, R.; et al. Mir-125a-5p regulation increases phosphorylation of fak that contributes to imatinib resistance in gastrointestinal stromal tumors. Exp. Cell. Res. 2018, 371, 287-296. [CrossRef]

26. Farhadi, E.; Zaker, F.; Safa, M.; Rezvani, M.R. Mir-101 sensitizes k562 cell line to imatinib through jak2 downregulation and inhibition of nf-kappab target genes. Tumour Biol. 2016, 37, 14117-14128. [CrossRef] [PubMed] 
27. San Jose-Eneriz, E.; Roman-Gomez, J.; Jimenez-Velasco, A.; Garate, L.; Martin, V.; Cordeu, L.; Vilas-Zornoza, A.; Rodriguez-Otero, P.; Calasanz, M.J.; Prosper, F.; et al. Microrna expression profiling in imatinib-resistant chronic myeloid leukemia patients without clinically significant abl1-mutations. Mol. Cancer 2009, 8, 69. [CrossRef]

28. Zimmerman, E.I.; Dollins, C.M.; Crawford, M.; Grant, S.; Nana-Sinkam, S.P.; Richards, K.L.; Hammond, S.M.; Graves, L.M. Lyn kinase-dependent regulation of mir181 and myeloid cell leukemia-1 expression: Implications for drug resistance in myelogenous leukemia. Mol. Pharmacol. 2010, 78, 811-817. [CrossRef]

29. Gao, T.; Han, Y.; Yu, L.; Ao, S.; Li, Z.; Ji, J. Ccna2 is a prognostic biomarker for er+ breast cancer and tamoxifen resistance. PLoS ONE 2014, 9, e91771. [CrossRef]

30. Bae, T.; Weon, K.Y.; Lee, J.W.; Eum, K.H.; Kim, S.; Choi, J.W. Restoration of paclitaxel resistance by cdk1 intervention in drug-resistant ovarian cancer. Carcinogenesis 2015, 36, 1561-1571. [CrossRef]

31. Coley, H.M.; Safuwan, N.A.; Chivers, P.; Papacharalbous, E.; Giannopoulos, T.; Butler-Manuel, S.; Madhuri, K.; Lovell, D.P.; Crook, T. The cyclin-dependent kinase inhibitor p57 (kip2) is epigenetically regulated in carboplatin resistance and results in collateral sensitivity to the cdk inhibitor seliciclib in ovarian cancer. Br. J. Cancer 2012, 106, 482-489. [CrossRef] [PubMed]

32. Chu, J.; Zhu, Y.; Liu, Y.; Sun, L.; Lv, X.; Wu, Y.; Hu, P.; Su, F.; Gong, C.; Song, E.; et al. E2f7 overexpression leads to tamoxifen resistance in breast cancer cells by competing with e2f1 at mir-15a/16 promoter. Oncotarget 2015, 6, 31944-31957. [CrossRef] [PubMed]

33. Saenz-Ponce, N.; Pillay, R.; de Long, L.M.; Kashyap, T.; Argueta, C.; Landesman, Y.; Hazar-Rethinam, M.; Boros, S.; Panizza, B.; Jacquemyn, M.; et al. Targeting the xpo1-dependent nuclear export of e2f7 reverses anthracycline resistance in head and neck squamous cell carcinomas. Sci. Transl. Med. 2018, 10. [CrossRef] [PubMed]

34. Ye, L.; Guo, L.; He, Z.; Wang, X.; Lin, C.; Zhang, X.; Wu, S.; Bao, Y.; Yang, Q.; Song, L.; et al. Upregulation of e2f8 promotes cell proliferation and tumorigenicity in breast cancer by modulating $\mathrm{g} 1 / \mathrm{s}$ phase transition. Oncotarget 2016, 7, 23757-23771. [CrossRef] [PubMed]

35. Tian, J.; Lin, Y.; Yu, J. E2f8 confers cisplatin resistance to er+ breast cancer cells via transcriptionally activating mastl. Biomed. Pharmacother. 2017, 92, 919-926. [CrossRef] [PubMed]

36. Carvajal, R.D.; Tse, A.; Schwartz, G.K. Aurora kinases: New targets for cancer therapy. Clin. Cancer Res. 2006, 12, 6869-6875. [CrossRef] [PubMed]

37. Lagarde, P.; Perot, G.; Kauffmann, A.; Brulard, C.; Dapremont, V.; Hostein, I.; Neuville, A.; Wozniak, A.; Sciot, R.; Schoffski, P.; et al. Mitotic checkpoints and chromosome instability are strong predictors of clinical outcome in gastrointestinal stromal tumors. Clin. Cancer Res. 2012, 18, 826-838. [CrossRef]

38. Yeh, C.N.; Yen, C.C.; Chen, Y.Y.; Cheng, C.T.; Huang, S.C.; Chang, T.W.; Yao, F.Y.; Lin, Y.C.; Wen, Y.S.; Chiang, K.C.; et al. Identification of aurora kinase a as an unfavorable prognostic factor and potential treatment target for metastatic gastrointestinal stromal tumors. Oncotarget 2014, 5, 4071-4086. [CrossRef]

39. Tsai, H.J.; Jiaang, W.T.; Shih, N.Y.; Fletcher, J.A.; Lin, M.J.; Yang, M.Y.; Chen, C.T.; Hsu, T.J.; Wu, C.C.; Lin, H.Y.; et al. Bpr1j373, a novel multitargeted kinase inhibitor, effectively suppresses the growth of gastrointestinal stromal tumor. Cancer Sci. 2018, 109, 3591-3601. [CrossRef]

40. Bai, C.; Liu, X.; Qiu, C.; Zheng, J. Foxm1 is regulated by both hif-1alpha and hif-2alpha and contributes to gastrointestinal stromal tumor progression. Gastric Cancer 2019, 22, 91-103. [CrossRef]

41. Nestal de Moraes, G.; Bella, L.; Zona, S.; Burton, M.J.; Lam, E.W. Insights into a critical role of the foxo3a-foxm1 axis in DNA damage response and genotoxic drug resistance. Curr. Drug. Targets 2016, 17, 164-177. [CrossRef] [PubMed]

42. Li, D.; Liu, X.; Lin, L.; Hou, J.; Li, N.; Wang, C.; Wang, P.; Zhang, Q.; Zhang, P.; Zhou, W.; et al. Microrna-99a inhibits hepatocellular carcinoma growth and correlates with prognosis of patients with hepatocellular carcinoma. J. Biol. Chem. 2011, 286, 36677-36685. [CrossRef] [PubMed]

43. Oneyama, C.; Ikeda, J.; Okuzaki, D.; Suzuki, K.; Kanou, T.; Shintani, Y.; Morii, E.; Okumura, M.; Aozasa, K.; Okada, M. Microrna-mediated downregulation of mtor/fgfr3 controls tumor growth induced by src-related oncogenic pathways. Oncogene 2011, 30, 3489-3501. [CrossRef] [PubMed]

44. Fingar, D.C.; Richardson, C.J.; Tee, A.R.; Cheatham, L.; Tsou, C.; Blenis, J. Mtor controls cell cycle progression through its cell growth effectors s6k1 and 4e-bp1/eukaryotic translation initiation factor 4e. Mol. Cell Biol. 2004, 24, 200-216. [CrossRef] [PubMed] 
45. Sachdeva, M.; Wu, H.; Ru, P.; Hwang, L.; Trieu, V.; Mo, Y.Y. Microrna-101-mediated akt activation and estrogen-independent growth. Oncogene 2011, 30, 822-831. [CrossRef] [PubMed]

46. Zhang, X.; He, X.; Liu, Y.; Zhang, H.; Chen, H.; Guo, S.; Liang, Y. Mir-101-3p inhibits the growth and metastasis of non-small cell lung cancer through blocking pi3k/akt signal pathway by targeting malat-1. Biomed. Pharmacother. 2017, 93, 1065-1073. [CrossRef] [PubMed]

47. Zhao, R.; Yang, H.Y.; Shin, J.; Phan, L.; Fang, L.; Che, T.F.; Su, C.H.; Yeung, S.C.; Lee, M.H. Cdk inhibitor p57 (kip2) is downregulated by akt during her2-mediated tumorigenicity. Cell Cycle 2013, 12, 935-943. [CrossRef]

48. Pothof, J.; Verkaik, N.S.; van IJcken, W.; Wiemer, E.A.; Ta, V.T.; van der Horst, G.T.; Jaspers, N.G.; van Gent, D.C.; Hoeijmakers, J.H.; Persengiev, S.P. Microrna-mediated gene silencing modulates the uv-induced DNA-damage response. EMBO J. 2009, 28, 2090-2099. [CrossRef]

49. De Hoon, M.J.; Imoto, S.; Nolan, J.; Miyano, S. Open source clustering software. Bioinformatics 2004, 20, 1453-1454. [CrossRef]

50. Saldanha, A.J. Java Treeview—extensible visualization of microarray data. Bioinformatics 2004, 20, 3246-3248. [CrossRef]

51. Johnson, W.E.; Li, C.; Rabinovic, A. Adjusting batch effects in microarray expression data using empirical bayes methods. Biostatistics 2007, 8, 118-127. [CrossRef] [PubMed]

52. McCall, M.N.; Bolstad, B.M.; Irizarry, R.A. Frozen robust multiarray analysis (frma). Biostatistics 2010, 11, 242-253. [CrossRef] [PubMed]

(C) 2019 by the authors. Licensee MDPI, Basel, Switzerland. This article is an open access article distributed under the terms and conditions of the Creative Commons Attribution (CC BY) license (http://creativecommons.org/licenses/by/4.0/). 